\title{
ERRATUM
}

\section{Grassland management practices in Chinese steppes impact productivity, diversity and the relationship}

\author{
Yingjun ZHANG (凶) ${ }^{*}$, Wenjie LU*, Hao ZHANG, Jiqiong ZHOU, Yue SHEN \\ Department of Grassland Science, China Agricultural University, Beijing 100193, China
}

Frontiers of Agricultural Science and Engineering, 2018, 5(1): 57-63

The original version of this article unfortunately contained mistake. The presentation of Fig. 3 was incorrect. The corrected figure is given below:

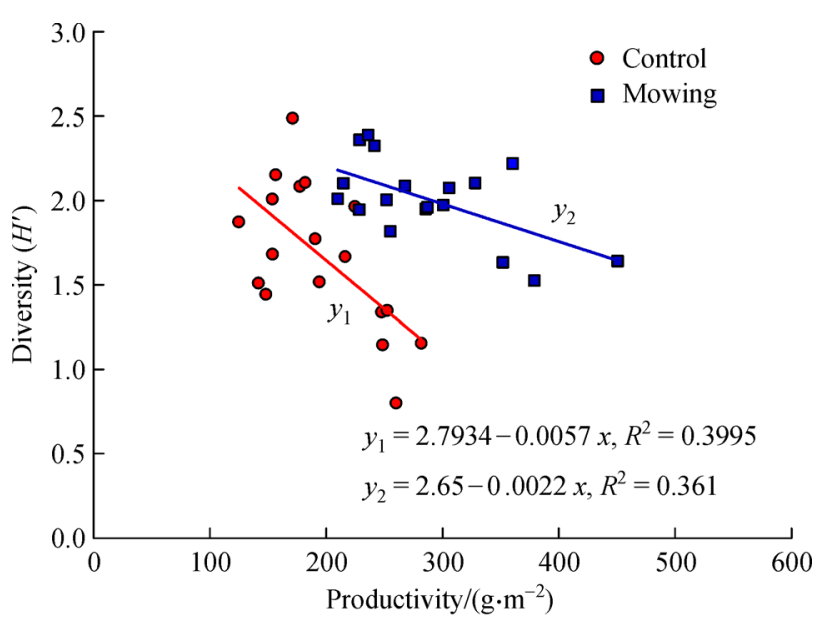

Fig. 3 Relationship between productivity and diversity in a mowing system

The online version of the original article can be found at https://doi.org/10.15302/J-FASE-2017192

Received August 8, 2017; accepted October 24, 2017

Correspondence: zhangyj@cau.edu.cn

${ }^{*}$ These authors contribute equally to the work

CC The Author(s) 2018. Published by Higher Education Press. This is an open access article under the CC BY license (http://creativecommons.org/licenses/by/4.0) 